\title{
A META-ANALYSIS OF SOCIO-DEMOGRAPHIC FACTORS FOR PERINATAL MORTALITY IN DEVELOPING COUNTRIES: A SUBGROUP ANALYSIS OF THE NATIONAL SURVEYS AND SMALL SCALE STUDIES
}

\author{
Yifru Berhan', Asres Berhan ${ }^{2}$
}

\begin{abstract}
BACKGROUND: Although the perinatal mortality in low income countries is about five-folds higher than in the high income countries, little is known about the association of socio-demographic factors with perinatal mortality. National and small scale studies so far reported have shown very contradictory results. The objective of this meta-analysis was to assess the association of perinatal mortality with selected sociodemographic factors.

METHODS: A computer based literature search was conducted mainly in the databases of African Journals Online, MEASURE Demographic and Health Survey (DHS), Google Scholar, HINARI, PUBMED, MEDLINE and the Cochrane Library. The inclusion criteria were: 1) studies that assessed the perinatal mortality in developing countries in relation to socio-demographic predictors and 2) studies published in English and conducted after the year 1990. Subgroup meta-analyses of perinatal mortality were performed for mothers' age, residence, educational level and wealth status. Sensitivity analysis and heterogeneity testing were done.

RESULTS: In this meta-analysis, several inconsistent associations of perinatal mortality with the selected socio-demographic variables were observed in the primary studies level, both DHS and small scale studies. However, the overall odds ratio (OR) demonstrated statistically significant association of perinatal mortality with low maternal age $(O R=1.2)$ and short birth interval $(O R=1.4)$ but was not influenced by the mothers' residence, low educational level and household wealth index. Very consistently, the highest perinatal mortality rates reported when the birth intervals were either too short ( $<15$ months) or too long ( $>39$ months).

CONCLUSION: Because of the disagreement among previous studies, the present study demonstrated a small effect size on the increased risk of perinatal mortality among women who were pregnant during teenage ages and gave birth too frequently or after a long interval. Therefore, to confirm the strong predictors of perinatal mortality, further studies on sociodemographic factors are needed.

KEYWORDS: birth interval, subgroup meta-analysis, mother's age, education, perinatal mortality
\end{abstract}

DOI: http://dx.doi.org/10.4314/ejhs.v24i1.5S

\section{INTRODUCTION}

The perinatal mortality rate (PMR) is one of the best indicators of the health status of a population in general, and the maternal and neonatal care in particular. To capitalize its significance, it has been believed that The Millennium Development Goal of reducing child mortality by two-thirds by 2015 would be difficult to achieve without reducing the perinatal deaths (1).

\footnotetext{
${ }^{1}$ Hawassa University, College of Medicine and Health Sciences, Department of Gynecology-Obstetrics

${ }^{2}$ Hawassa University, College of Medicine and Health Sciences, Department of Pharmacology

Corresponding Author: Yifru Berhan, Email: yifrub@yahoo.com
} 
Because of a marked difference in the quality of services for pregnant women and their babies, the perinatal mortality in low income countries is about five-folds higher than in the high income countries (2). In other words, the poor health care for pregnant women before and during birth and the lack of resuscitative and therapeutic interventions for sick newborns are usually recognized as a factor for the high perinatal mortality in low income countries (3). It has been also pointed out that multiple socioeconomic and demographic factors play important roles in the rise or decline of perinatal mortality (4-7).

Among others, maternal age and level of education at birth, birth intervals less than 2 years, rural life and low income were reported as determinant factors for high perinatal mortality (3, 8). In several demographic and health surveys (DHS) and small scale studies, these variables have been assessed in relation to perinatal mortality. However, the review of the proportion of perinatal mortality in relation to these variables has shown inconsistent results. Similarly, with regard to association of perinatal mortality with age of the mother at birth of the index fetus or neonate, several small scale studies from different countries have also reported inconsistent results (9-22).

Firstly, taking the inconsistent findings into account, this meta-analysis was intended to explore the pooled effect of the selected socioeconomic and demographic variables on perinatal mortality in studies included. Secondly, it is known that there are several hospital based studies that have explored the direct and indirect causes of perinatal mortality and have shed light on their magnitudes in different settings (23-27). However, to the best of authors' knowledge, there is no meta-analysis that investigated the association of socio-economic and demographic factors with perinatal mortality in the world.

Thus, the objective of this meta-analysis was to assess the association of perinatal mortality with mother's age and level of education at birth, area of residence, household wealth index and birth interval in selected developing countries.

\section{METHODS}

\section{Search strategy}

A computer based literature search was conducted in the databases of African Journals Online, Google Scholar, HINARI, PUBMED, MEDLINE and the Cochrane Library. The literature search was further strengthened by searching the reference lists of retrieved articles. All the DHS data included in the meta-analyses were retrieved from the MEASURE DHS website. During the search for articles, the following search terms were used: perinatal mortality, early neonatal mortality, stillbirth, countries name, mother's residence, age, wealth index, educational level and birth interval of the index fetus or neonate. The selected search terms were combined alternatively with the Boolean logic (AND, OR and NOT).

\section{Inclusion criteria and study selection}

The predetermined inclusion criteria were: 1) studies that assessed the perinatal mortality in developing countries in relation to sociodemographic predictors and 2) studies published in English and conducted after the year 1990. Study selection was conducted in two stages by both authors independently; first the abstracts of all the retrieved literatures were reviewed and then grouped as "eligible for full document review" and "ineligible for full document review". Secondly, all the literatures grouped as "eligible for full document review" were reviewed in detail and grouped as "eligible for this meta-analysis" and "ineligible for this meta-analysis". When there were disagreements in the grouping of articles, decision was made by discussion and by reviewing the articles together. In this metaanalysis, two types of studies were included: national representative DHSs and small scale studies (not nationally representative).

\section{Data extraction}

Using Excel spreadsheets, data extractions were also performed by both authors using similar data extraction template. From the included small scale studies, the following information was abstracted: name of the first author, year of publication, the country in which the study was conducted, study period, data source, mothers' age at birth, education level, wealth status, residence and birth interval. Similarly, from the DHS of the selected countries (Azerbaijan, Bangladish, Burkina Faso, Burundi, Ethiopia, Kenya, Ghana, Guyana, 
Malawi, Maldives, Lesotho, Liberia, Nambia, Nepal, Nigeria, Pakistan, Phillipines, Senegal, Sierra Leone, Tanzania, Uganda, Zambia and
Zimbabwee), residence, mothers' age at birth, birth interval, mothers' education level and wealth status were abstracted.

Table 1: General characteristics of the included small scale studies

\begin{tabular}{|c|c|c|c|c|c|}
\hline Authors & $\begin{array}{l}\text { Year of } \\
\text { publication }\end{array}$ & Study period & Location & Data source & Study design \\
\hline Andargie $\mathrm{G}$ et al (15) & 2013 & $\begin{array}{l}\text { November } 2009 \\
\text { to August } 2011\end{array}$ & Ethiopia & Community based & Prospective cohort \\
\hline Diallo et al (16) & 2010 & $\begin{array}{l}\text { June } 2006 \text { to } \\
\text { May } 2007\end{array}$ & $\begin{array}{l}\text { Burkina } \\
\text { Faso }\end{array}$ & Community based & Prospective cohort \\
\hline Ekure et al (17) & 2011 & $\begin{array}{l}\text { June } 2002 \text { to } \\
\text { November } 2002\end{array}$ & Nigeria & $\begin{array}{l}\text { Health facility } \\
\text { based }\end{array}$ & Prospective cohort \\
\hline Engmann $\mathrm{C}$ et al (18) & 2011 & 2002 to 2008 & Ghana & Community based & Prospective cohort \\
\hline Fawole AO et al (19) & 2011 & $\begin{array}{l}\text { October } 2004 \text { to } \\
\text { February } 2005\end{array}$ & Nigeria & $\begin{array}{l}\text { Health facility } \\
\text { based }\end{array}$ & Cross sectional study \\
\hline $\begin{array}{l}\text { Abu Habib NA et al } \\
(20)\end{array}$ & 2011 & 1999 to 2006 & Tanzania & $\begin{array}{l}\text { Health facility } \\
\text { based }\end{array}$ & Prospective cohort \\
\hline $\begin{array}{l}\text { Hinderaker SG et al } \\
\text { (21) }\end{array}$ & 2003 & $\begin{array}{l}\text { January } 1995 \text { to } \\
\text { March } 1996\end{array}$ & Tanzania & $\begin{array}{l}\text { Health facility } \\
\text { based }\end{array}$ & Prospective cohort \\
\hline Lansky S et al (22) & 2007 & 1999 & Brazil & $\begin{array}{l}\text { Health facility } \\
\text { based }\end{array}$ & Prospective cohort \\
\hline $\begin{array}{l}\text { Matendo RM et al } \\
(23)\end{array}$ & 2011 & $\begin{array}{l}\text { June-December } \\
2005\end{array}$ & $\begin{array}{l}\text { D. Republic } \\
\text { Congo }\end{array}$ & Community based & Prospective cohort \\
\hline $\begin{array}{l}\text { Mo-suwan L et al } \\
(24)\end{array}$ & 2009 & 2000 to 2002 & Thailand & Community based & Prospective cohort \\
\hline $\begin{array}{l}\text { Nankabirwa } \mathrm{V} \text { et al } \\
(25)\end{array}$ & 2011 & $\begin{array}{l}\text { January } 2006 \text { to } \\
\text { May } 2008\end{array}$ & Uganda & Community based & Prospective cohort \\
\hline Olatinwo A et al (26) & 2000 & $\begin{array}{l}\text { January } 1996 \text { to } \\
\text { December } 1998\end{array}$ & Nigeria & $\begin{array}{l}\text { Health facility } \\
\text { based }\end{array}$ & Retrospective study \\
\hline Oti SO et al (27) & 2011 & 2003 & Nigeria & Community based & Cross sectional \\
\hline Pervin J et al (28) & 2012 & 2005 to 2009 & Bangladesh & Community based & Prospective cohort \\
\hline
\end{tabular}

\section{Included studies}

In this meta-analysis, national DHSs of 23 developing countries were included; 14 were from Sub-Saharan African countries (28). As shown in Figure 1 (flow chart), perinatal mortality as a search term in PUBMED database has identified 16054 literatures. After screening the titles, the initial literature search for the small scale studies on perinatal mortality has identified 118 potential articles. Depending on the titles and the abstracts proximity to the objectives of this study, 74 articles were retrieved for further screening. After the full document review of all the retrieved articles, 14 articles met the predetermined inclusion criteria of this meta-analysis (9-22). Eleven studies of the fourteen were conducted in Sub-Saharan Africa $(9-15,17,19-21)$; the remaining three were from Brazil, Thailand and Bangladesh (16, 18, 22), one from each. 


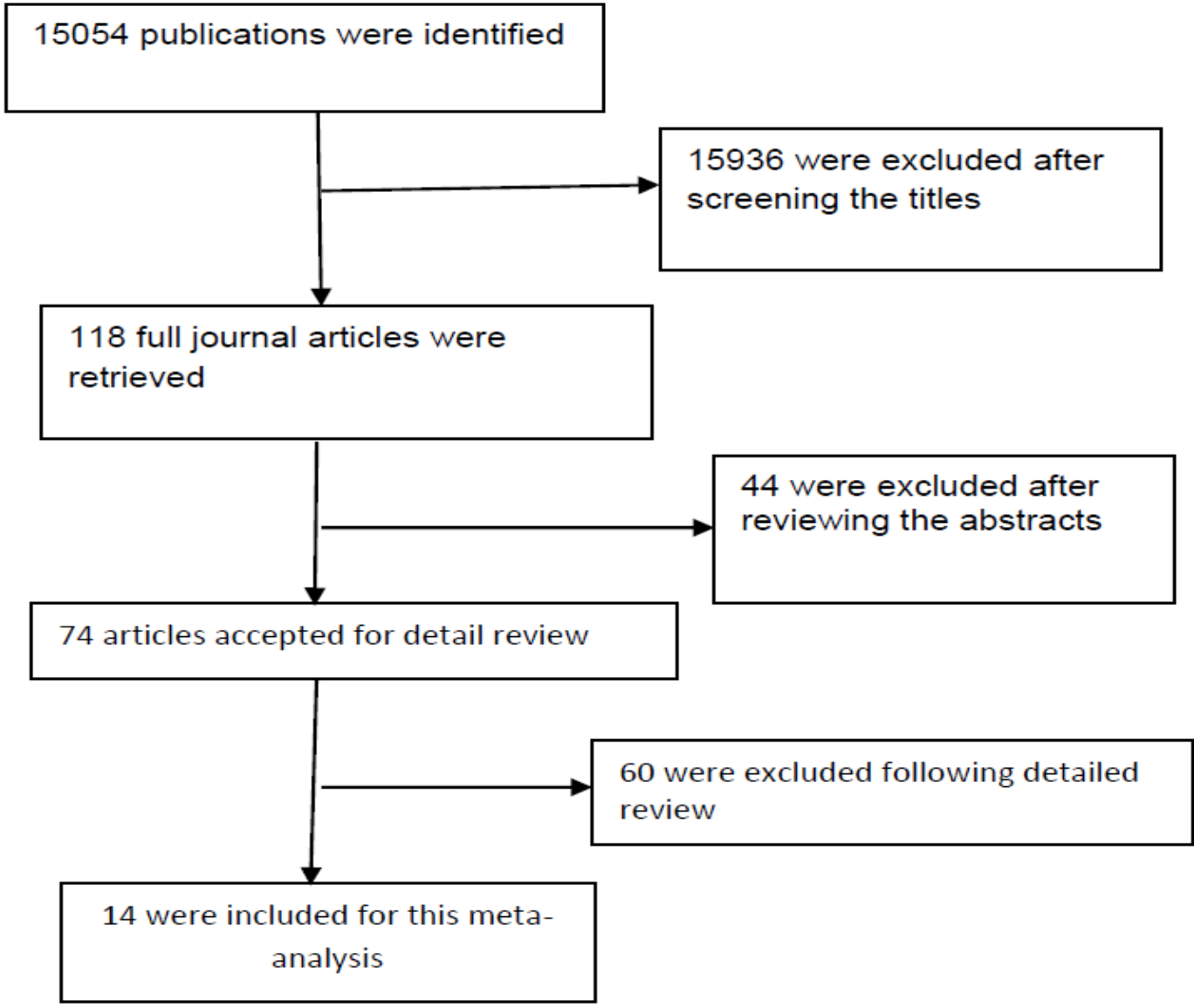

Figure 1: Flow diagram showing the process of small scale studies selection

\section{Operational definition}

As stated by International Monetary Fund and the World Bank (29), developing countries were defined according to their Gross National Income (GNI) per capita per year. Countries with GNI of US\$ 11,905 and less were categorized as developing countries.

In all DHS, similar parameters were used to assess the wealth status of a household (such as the source of water, type of toilet facility, materials used for housing construction, ownership of various durable goods, ownership of agricultural land, ownership of domestic animals and ownership and use of mosquito nets) (28).

In line with WHO and UNFPA, this review defines adolescent as the age category of 10-19 years for both female and male (30). In all DHS and small scale studies, perinatal mortality includes all neonatal deaths of less than seven days of age and fetal deaths after 28 weeks of gestation, which is known as perinatal mortality-I (31).

\section{Statistical analysis}

Before the actual meta-analyses were performed, all the socio-demographic variables were dichotomized purposively to make fit for the meta-analysis software. Since a significant heterogeneity was found in the fixed effects model, in all the meta-analyses, the random effects model was used to determine the Mantel-Haenszel odds ratios (OR) and the $95 \%$ confidence intervals (95\% CI). When the 95\% CI did not include the number 1 , it was considered as statistically significant. $\mathrm{I}^{2}$ statistics was used to assess the heterogeneity of the included studies. $\mathrm{I}^{2}$ value greater than or equal to $50 \%$ was considered as statistically significant.

Subgroup meta-analyses were performed for the following variables: residence, mothers' age at birth, mothers' education level and wealth status. 
Sensitivity analysis (excluding any of the included studies from the analysis at a time) was also conducted to determine the stability of the overall values to outliers. Publication bias was assessed with funnel plots. All the statistical analyses were performed using Review Manager 5 software (RevMan5).

\section{RESULTS}

As presented in Figure 2, in both subgroup DHS and small scale studies, perinatal mortality was significantly associated with mothers' ages of less than twenty years (overall OR $=1.19 ; 95 \% \mathrm{CI}$, 1.07 to 1.33 ). Contrary to the overall OR, perinatal mortality in Uganda was associated with mothers' age of twenty years and above and in six more countries (Liberia, Lesotho, Kenya, Philippines, Guyana and Zimbabwe) and three small scale

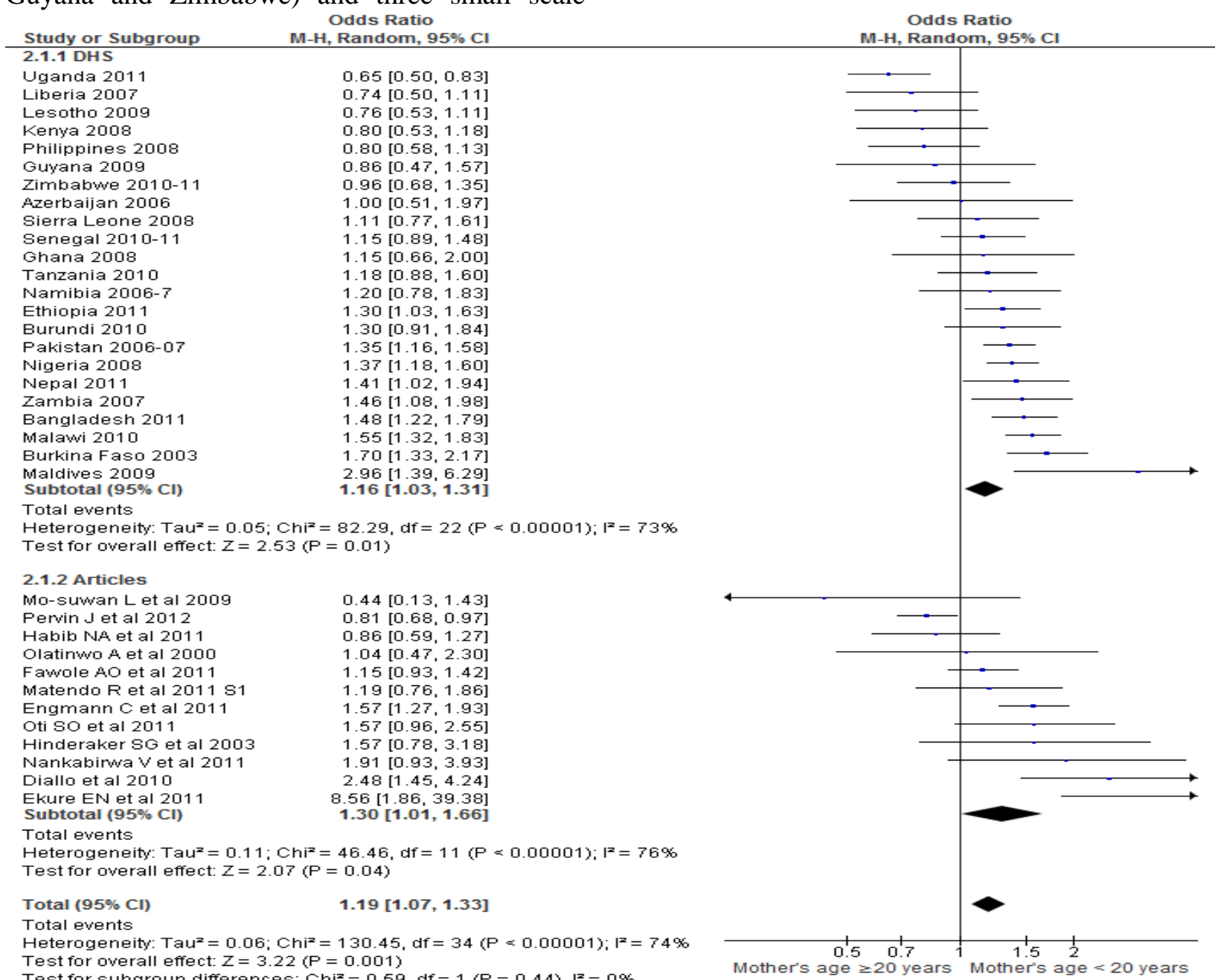

studies $(14,18,22)$, more perinatal mortality was observed among women aged 20 years and above.

Heterogeneity testing demonstrated the existence of significant inconsistency across the included DHS $\left(\mathrm{I}^{2}=73 \%\right)$ and small scale studies $\left(\mathrm{I}^{2}=76 \%\right)$. Nevertheless, within groups difference (DHS vs Articles) was not statistically significant $\left(\mathrm{I}^{2}=0 \%\right)$. Sensitivity analysis showed that the subtotal OR for small scale studies did not show statistically significant association with exclusion of any of the six studies $(11,12,15,27,19,21)$. The sensitivity analysis, however, did not significantly change the overall OR; there was little change in the overall OR with significant change in the subgroup small scale studies OR. The subtotal OR for subgroup DHS analysis also remained stable with removal of any of the DHS data.

Figure 2: Subgroup meta-analysis on association of maternal age at birth with perinatal mortality 
As shown in Figure 3, the meta-analysis of perinatal mortality in relation to residence did not show a statistically significant difference between mothers' rural and urban residence (overall $\mathrm{OR}=$ $0.93 ; 95 \%$ CI, 0.83 to 1.05$)$. However, in seven countries DHS (Azerbaijan, Burkina Faso, Guyana, Pakistan, Sierra Leone, Tanzania, and Zimbabwe) and one small scale study (19), the perinatal mortality was significantly higher in urban than in rural areas. In three countries DHS (Nigeria, Ghana and Philippines), perinatal mortality was significantly higher in rural than in urban areas. Heterogeneity testing revealed the presence of significant variability among the included DHSs and small scale studies $\left(\mathrm{I}^{2}=78 \%\right)$. The sensitivity analysis, however, attested the stability of both the subgroup and the overall ORs.

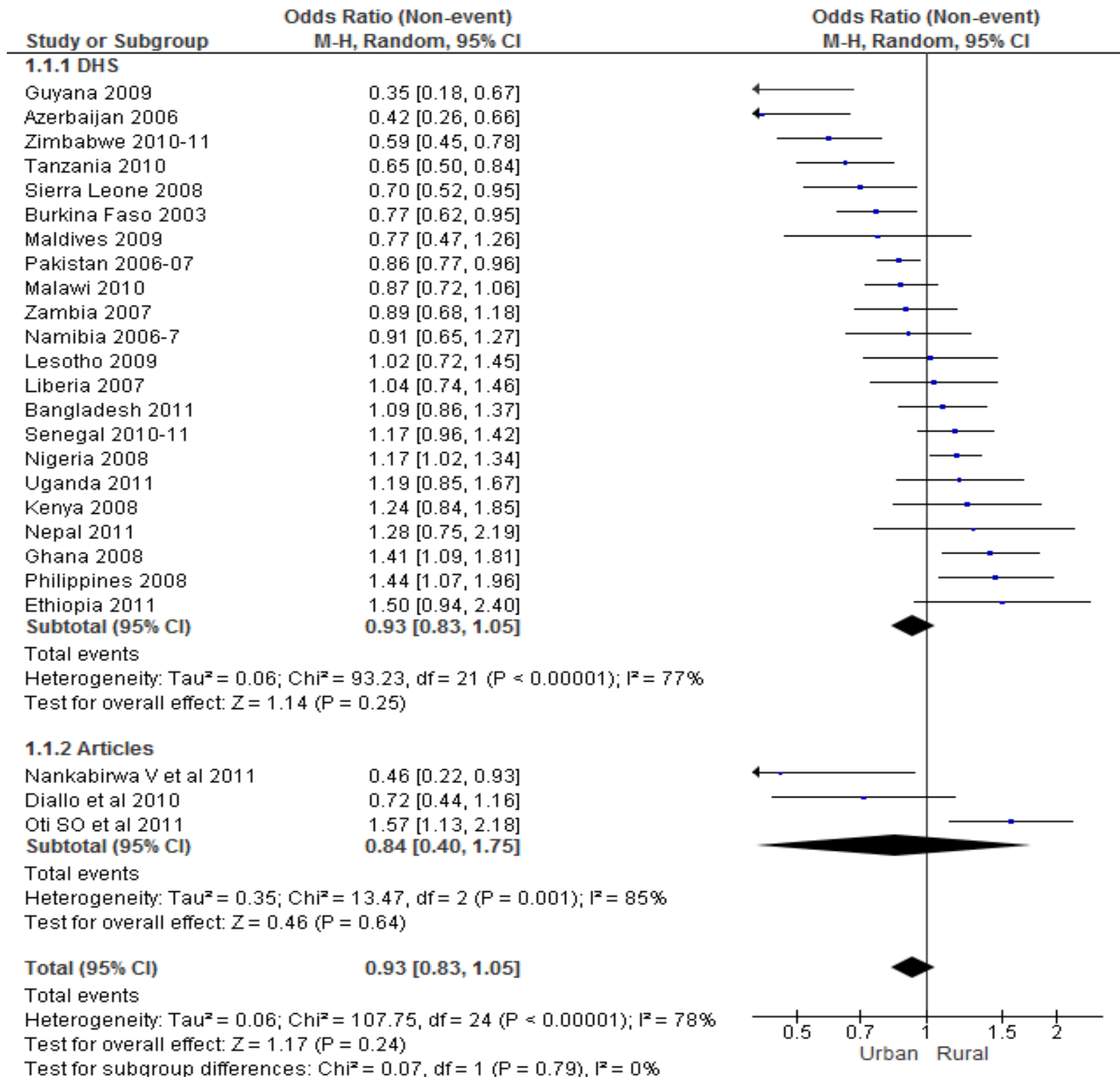

Figure 3: Subgroup meta-analysis on association of mother's residence at birth with perinatal mortality

Figure 4 shows the absence of a statistically significant association of perinatal mortality with the mothers' educational level at the time of the birth of the index fetus or neonate (overall OR = 
1.14; $95 \%$ CI, 1.00 to 1.29$)$. However, with the exclusion of one of the DHS data (Bangladesh, Sierra Leone, Guyana, Tanzania, Burkina Faso, Liberia, Azerbaijan and Kenya) favoring high perinatal mortality among women educated to secondary and above level, the overall OR demonstrated a statistically significant association of perinatal mortality with low level of education.

The subtotal odds ratios did not show statistically significant change with the exclusion of either the DHS or small scale studies; nearly one-third of the DHS data showed an increased perinatal mortality with increased level of mothers' education while the other one third showed an increased perinatal mortality with low level of mothers' education. The majorities of small scale studies demonstrated the inverse relation of perinatal mortality with the mother's level of education.

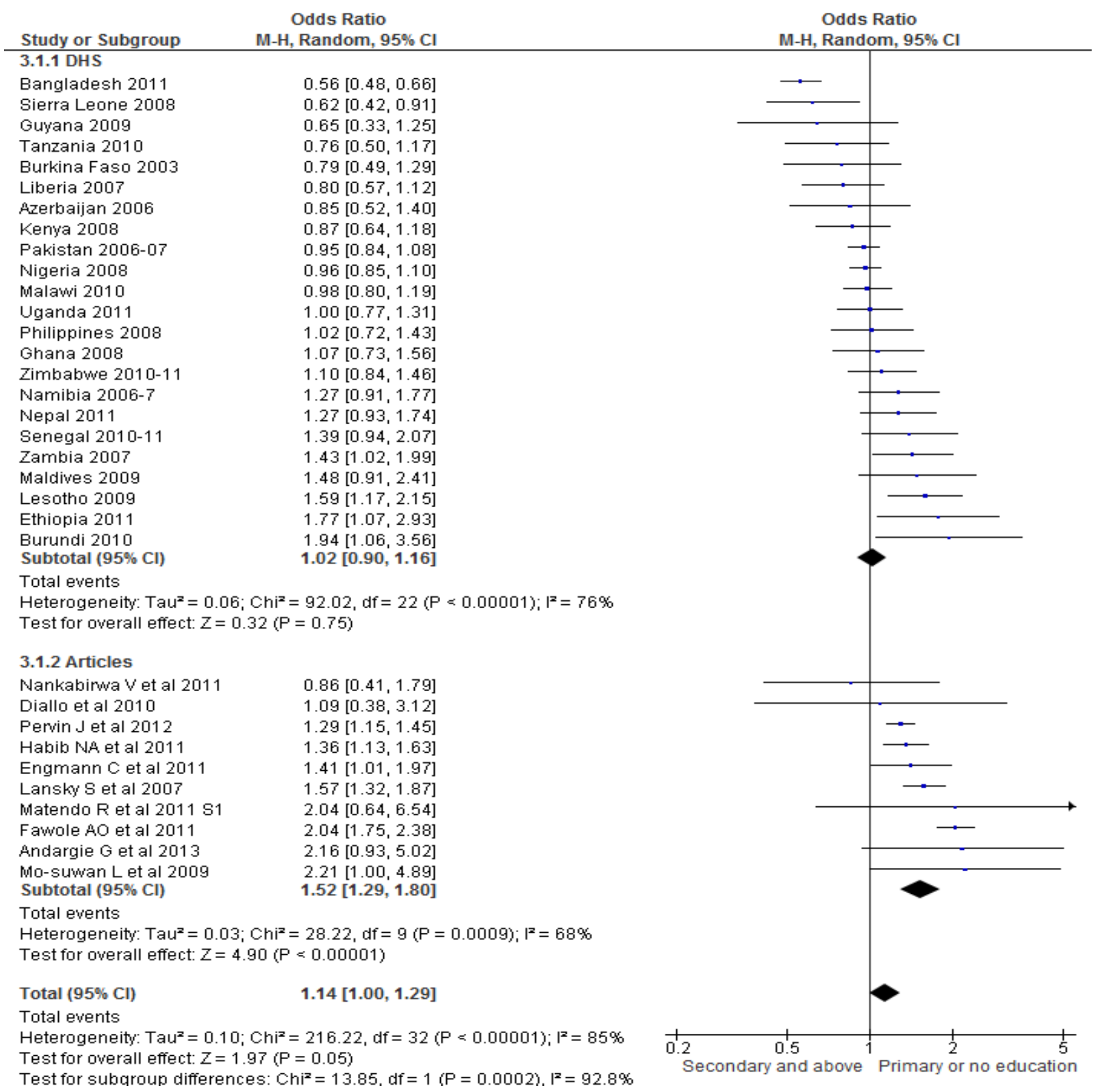

Figure 4: Subgroup meta-analysis on association of mother's educational level at birth with perinatal mortality 
In Figure 5, a similar pattern of association was observed with regard to perinatal mortality and wealth index. With regard to sub group DHS data, in some countries (Liberia, Ghana and Tanzania), the perinatal mortality was high among women with high wealth index. In the majority of the countries, however, perinatal mortality was not associated with wealth index. Small scale studies showed a weak association of perinatal mortality with wealth index. In the sensitivity analysis, the OR in the subgroup or overall did not significantly change.

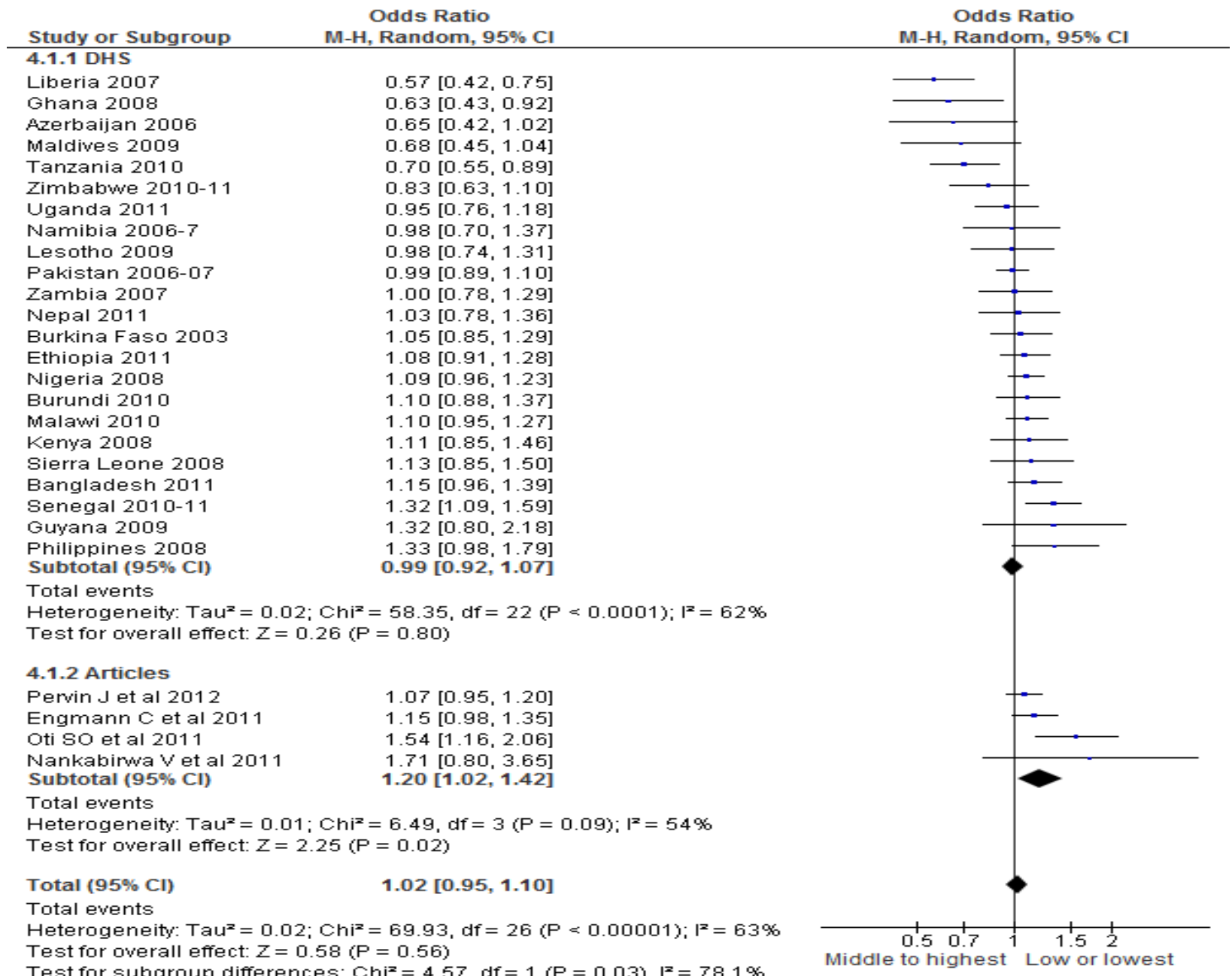

Figure 5: Subgroup meta-analysis on association of mother's wealth index at birth with perinatal mortality

As shown in Figure 6, birth interval less than 27 months was a strong predictor of perinatal mortality (overall $\mathrm{OR}=1.4 ; 95 \% \mathrm{CI}, 1.24$ to 1.50). The odds of perinatal mortality among women who gave birth in less than about two years was more than 1.5 in seven countries (Nepal, Kenya, Malawi, Burkina Faso, Nigeria, Burundi and Zimbabwe). The heterogeneity testing revealed moderate variation among the included DHS data $\left(I^{2}=57 \%\right)$. The sensitivity analysis has also shown the stability of the overall OR with the exclusion of any of the DHS datum favoring either increased or decreased perinatal mortality. 


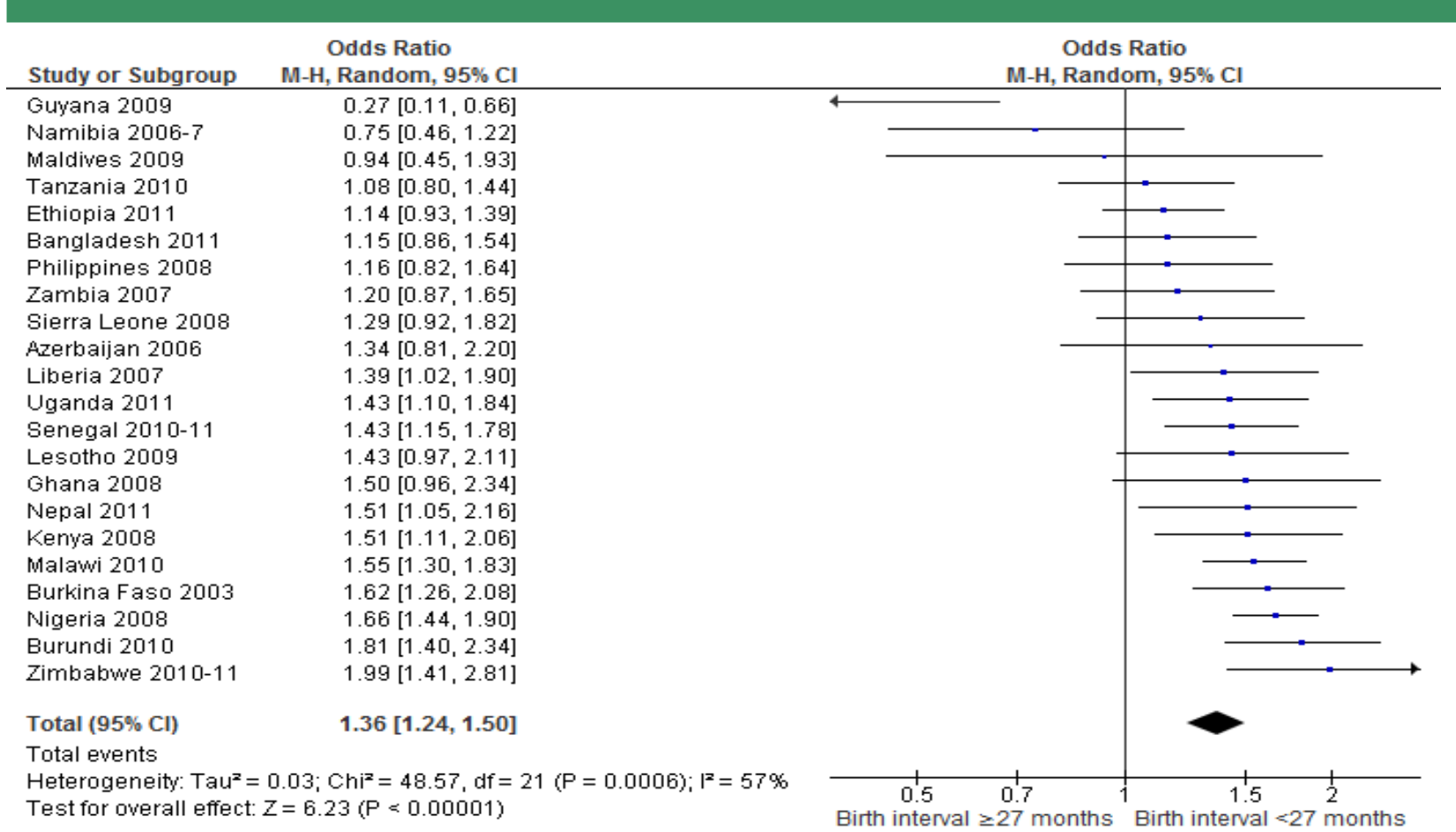

Figure 6: Meta-analysis on association of birth interval with perinatal mortality

Figure 7 shows the distribution of perinatal mortality rate against the stratified birth interval. Consistently, the highest and lowest perinatal mortality occurred when the birth intervals were <
15 and 27-38 months, respectively. Increasing the birth interval to 39 months and above was also consistently associated with increased perinatal mortality.

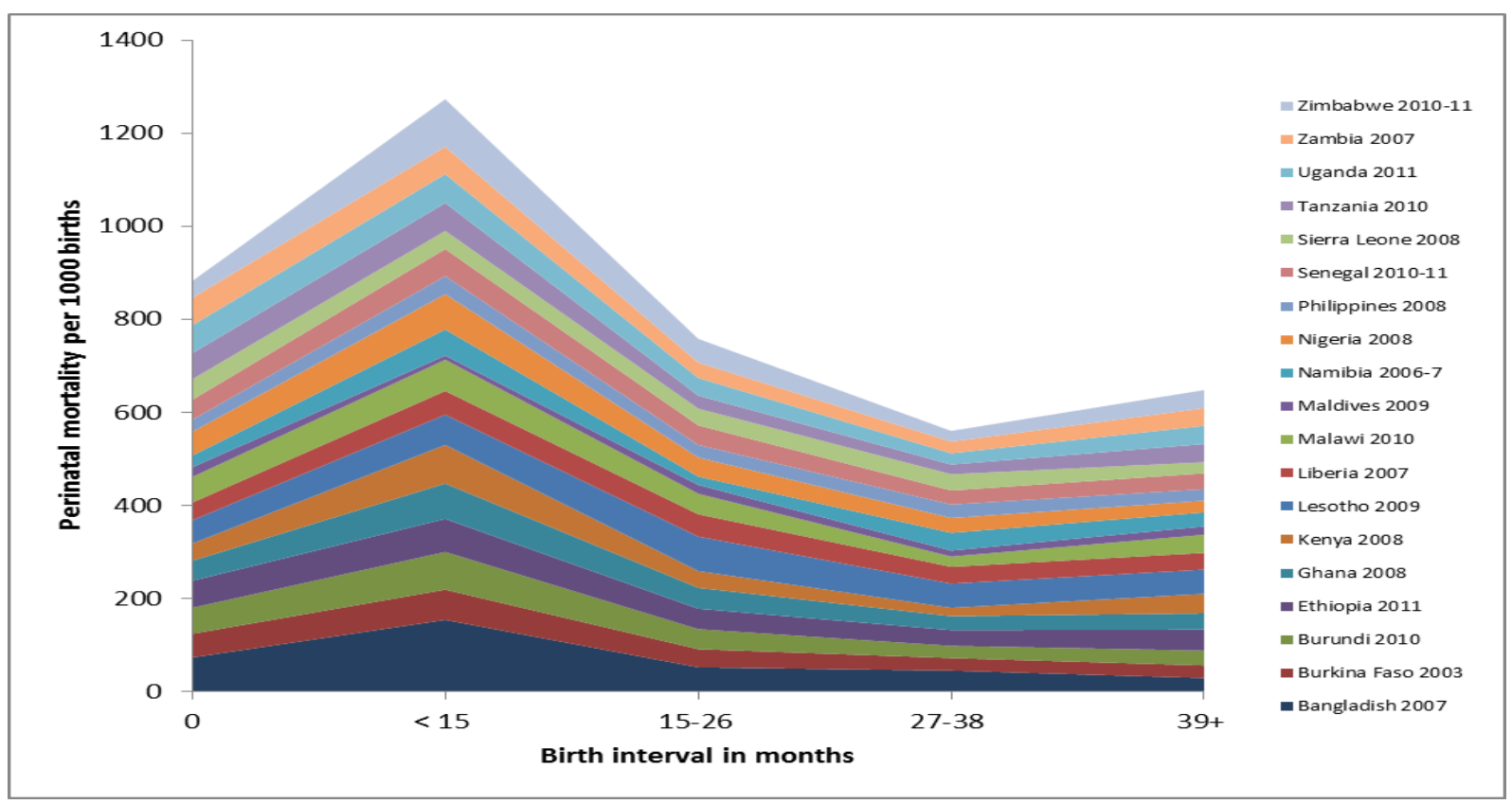

Figure 7: The pattern of perinatal mortality rate in relation to birth interval 


\section{DISCUSSION}

The overall odds ratios in this meta-analysis demonstrated the association of perinatal mortality with adolescent pregnancy, low level of maternal education (with the exclusion of one of the DHS data) and short birth interval. But, the perinatal mortality was not influenced by area of residence and household wealth index. With regard to increased risk of perinatal mortality among babies of adolescent mothers, although there are studies not included in this meta-analysis indicating that adolescent pregnancy was not associated with increased risks of perinatal mortality (32-34), several other studies showed the increased risk of perinatal mortality among adolescent pregnant women (35-39).

However, it should be noted that the effect size of adolescent pregnancy on perinatal mortality reported in this review and other primary studies was not big enough to make a strong conclusion. This finding probably indicates the need of further research. Short of this, the reason for the small increase in perinatal mortality among adolescent mothers is the increased risk of obstetric complications in this age category (hypertensive disorders, preterm labor, obstructed labor, intrauterine growth restriction, low birth weight, infections) among adolescent pregnant women (35-44). Why obstetric complications are more common in teenagers than in adults is not exactly known. Some speculations are: since adolescent pregnant women still continue growing with high energy demand, they may compete for nutrients with the developing fetus $(38,45)$; secondly, they are likely to have contracted or poorly developed pelvis, short stature and low weight gain before and during pregnancy (43).

Furthermore, significant numbers of adolescent pregnancies are unplanned (46) and associated with higher perinatal mortality and morbidity $(47,48)$, and less likely to access or receive adequate antenatal care (49). The finding of more perinatal mortality in some countries among women aged 20 years and above at the birth of the index fetus or neonate might be influenced by expected high perinatal mortality among old pregnant women (50) or some other factors not controlled in this analysis. Literature review has also shown that there are other socioeconomic factors for increased perinatal mortality among babies of teenage mothers: lack of antenatal care, low educational level, unmarried status, psychological stress, use of illicit drugs and polygamous marriage $(32,34,51)$.

Otherwise, although several case-control, cross-sectional and retrospective studies consistently reported the strong association of perinatal mortality with living in rural areas and low socioeconomic status $(3,50-54)$, this analysis did not show statistically significant association of perinatal mortality with these variables.

By design, since all the DHS data were collected for five years preceding each survey, the chance of recall bias is also expected to be high in all areas but may be more in the rural areas and less educated persons. As a result, some of the perinatal deaths might have been under reported in the rural areas. It has been already noted that most perinatal deaths in developing countries are unseen and undocumented since the majority of births take place at home $(3,55-57)$.

On the other hand, although the overall odds ratio demonstrated a statistically significant association of perinatal mortality with maternal primary or no education levels (with the exclusion of one of the DHS data), mainly due to the pool effect of small scale studies $(9,12-14,16-18)$, the DHS data were not consistent; the perinatal mortality report of the ten countries was almost the opposite of that of the other ten countries. This is probably additional evidence that strengthens the possibility of an association of perinatal mortality with multiple other socio-demographic and obstetric factors. Despite this limitation and the small effect size observed in this analysis, other small scale studies have also identified low levels of education as an important determinant of high perinatal mortality even in high income countries $(51,58,59)$.

With regard to association of birth interval and perinatal mortality, literature review has shown that optimal inter pregnancy interval is not exactly known $(60,61)$. In this meta-analysis, the finding of a very consistent increased risk of perinatal mortality with decreased birth interval in the majority of the included countries may be taken as one of the strongest predictors of perinatal mortality. Small scale studies from developed and developing countries outside Africa have also shown similar results (61-66). However, it should be noted that perinatal mortality was also 
higher in almost all included countries when the inter pregnancy interval was thirty nine months and above. In other words, although it was observed that the peak and nadir of perinatal mortality were with birth interval less than one year and between two and three years, respectively, there was also a consistent increase in perinatal mortality among women who gave birth after long birth interval. The increased risk of perinatal mortality with increased inter pregnancy interval was also reported by several other studies (61, 66-68).

This meta-analysis has several limitations. Since the meta-analysis softwares do not allow performing multivariate analysis, we were unable to assess the effect of one socio-demographic variable over the other. Secondly, the presence of significant heterogeneity among both DHS and small scale studies and the variation in research design among the included studies may limit the generalizability of the findings to countries where the studies were conducted. Small scale studies not written in English were not included.

In conclusion, as the effect sizes showed, this meta-analysis did not demonstrate a strong association of perinatal mortality with the selected variables. As a result, more robust primary studies are highly recommended to settle the true predictors of perinatal mortality.

\section{ACKNOWLEDGEMENT}

We would like to thank PANE and KMG Ethiopia for the modest financial support granted for this review. We are also grateful to UNFPA Ethiopia for their generous financial support to cover the publication fee.

\section{REFERENCES}

1. Haines A, Cassels A. Can the Millennium Development Goals be attained? BMJ 2004; 329: 394-397.

2. World Health Organization. Neonatal and perinatal mortality: country, regional \& global estimates. Geneva, Switzerland, 2006.

3. Surekha AT, Kumar N. Socio demographic factors affecting perinatal mortality- A study in a rural setup. IOSR Journal of Pharmacy 2012; 2(4): 43-46).
4. Tariq A. Perinatal Mortality: A Dissection of Social Myths, Socioeconomic Taboos and Psychosocial Stress. J Neonatal Biol 2012; 1:111. doi:10.4172/2167-0897.1000111.

5. Kozuki N, Lee ACC, Silveira MF, et al. The associations of parity and maternal age with small-for-gestational-age, preterm, and neonatal and infant mortality: a meta-analysis. BMC Public Health 2013; 13(Suppl 3):S2 doi:10.1186/1471-2458-13-S3-S2

6. Lawn JE, Cousens S, Zupan J. 4 million deaths: When? Where? Why? The Lancet 2005; 365 (9462):891 - 900.

7. Rahman S, Salameh K, Bener A, Ansari EL. Socioeconomic associations of improved maternal, neonatal, and perinatal survival in Qatar. Int J Wom Health 2010; 2:311-318.

8. Ben-Shlomo Y, White IR, Marmot M. Does the variation in socioeconomic characteristics of an area affect mortality? Br Med J 1996; 312:1013 -14.

9. Andargie G, Berhane Y, Worku A, Kebede Y. Predictors of perinatal mortality in rural population of Northwest Ethiopia: a prospective longitudinal study. BMC Public Health 2013; 13:168. http://www.biomedcentral.com

10. Diallo AH, Meda N, Zabsonré E, Sommerfelt $\mathrm{H}$, Cousens S, Tylleskär T. Perinatal mortality in rural Burkina Faso:

a prospective community-based cohort study. BMC Pregnancy Childbirth 2010; 10:45. http://www.biomedcentral.com

11. Ekure EN, Ezeaka VC, Iroha E, Egri-Okwaji M. Prospective audit of perinatal mortality among inborn babies in a tertiary health center in Lagos, Nigeria. Niger $J \quad C l i n$ Pract 2011; 14(1):88-94.

12. Engmann C, Walega P, Aborigo RA, et al. Stillbirths and early neonatal mortality in rural Northern Ghana. Trop Med Int Health 2012; 17(3):272-82.

13. Fawole AO, Shah A, Tongo O, et al. Determinants of perinatal mortality in Nigeria. Int $J$ Gynaecol Obstet 2011; 114(1):37-42.

14. Abu Habib N, Wilcox AJ, Daltveit AK, et al. Birthweight, preterm birth and perinatal mortality: a comparison of black babies in Tanzania and the USA. Acta Obstet Gynecol Scand 2011; 90(10):1100-6. 
15. Hinderaker SG, Olsen BE, Bergsjø PB, et al. Perinatal mortality in northern rural Tanzania. J Health Popul Nutr 2003; 21(1):8-17.

16. Lansky S, França E, Kawachi I. Social inequalities in perinatal mortality in Belo Horizonte, Brazil: the role of hospital care. Am J Public Health 2007; 97(5):867-73.

17. Matendo RM, Engmann CM, Ditekemena JD, et al. Challenge of perinatal mortality in rural Congo: findings of a prospective, population-based study. $J$ Health Popul Nutr 2011; 29(5):532-40.

18. Mo-suwan L, Isaranurug S, Chanvitan $\mathrm{P}$, et al. Perinatal death pattern in the four districts of Thailand: findings from the Prospective Cohort Study of Thai Children (PCTC). J Med Assoc Thai 2009; 92(5):660-6.

19. Nankabirwa V, Tumwine JK, Tylleskär T, Nankunda J, Sommerfelt H. Perinatal mortality in eastern Uganda: a community based prospective cohort study. PLoS One 2011; 9; 6(5):e19674. doi: 10.1371/journal.pone.0019674.

20. Olatinwo A, Anate A, Alao MO. Determinants of perinatal mortality among breech delivery in a Nigerian teaching Hospital. Sahel Medical Journal 2000; 3 (1): 26-29.

21. Oti SO, Odimegwu C. Perinatal Mortality in Nigeria: Do Place of Delivery and Delivery Assistants Matter? The Open Demography Journal 2011; 4: 1-10.

22. Pervin J, Moran A, Rahman M, et al. Association of antenatal care with facility delivery and perinatal survival -a populationbased study in Bangladesh. BMC Pregnancy Childbirth 2012; $\quad 12: 111$. http://www.biomedcentral.com

23. Caldwell J, Mc Donald P. Influence of Maternal Education on infant and child mortality: levels and causes. Health Policy Educ 1982; 2:251-256.

24. Gaym A. Perinatal mortality audit in Jima hospital, South Western Ethiopia, 1990-1999. Ethiop J Health Dev 2000; 14 (3): 335-343.

25. Van Roosmalen J. Perinatal mortality in rural Tanzania. Br J Obstet Gynaecol 1989; 96(7): 827-34.

26. Elamin S, Langhoff-Roos J, Boedker B, Ibrahim SA, Ashmeig AL, Lindmark G. Classification of perinatal death in a developing country. Int $J$ Gynecol Obstet 2003; 80(3): 327-33.

27. Federal Ministry of Health of Ethiopia, UNICEF, UNFPA, WHO, AMDD. National baseline assessment for emergency obstetric and newborn care. Ethiopia 2008.

28. Publication search by country (DHS): http://www.measuredhs.com/pubs/

29. The International statistics institute. Retrived in 2014 from: http://www.isiweb.org/component/content/article/5-

root/root/81-developing. International Monetary Fund (IMF), World Economic Outlook-Recovery Strengthens, Remains Uneven (Washington, April 2014). www.imfbookstore.org

30. The health of youth. Document A42/Technical discussions//2. Geneva. WHO. 1989. Available from: whqlibdoc.who.int/hq.

31. World Health Organization. Neonatal and perinatal mortality: country, regional \& global estimates. Geneva, Switzerland, 2006. http://whqlibdoc.who.int/publications/2006/92 41563206_eng.pdf

32. Lubarsky Schiff E, Friedman SA, Mercer BM, Sibai BM. Obstetric characteristics among nulliparas under age 15. Obstet Gynecol 1994; 84: 365-8.

33. Lawlor DA, Shaw M. Too much too young? Teenage pregnancy is not a public health problem. Int J Epidemiol 2002; 31(3): 552-4.

34. Otterblad Olausson PM, Cnattingius S, Goldenberg RL. Determinants of poor pregnancy outcomes among teenagers in Sweden. Obstet Gynecol 1997; 89:451-7.

35. Jolly MC, Sebire N, Robinson HS, Regan L. Obstetric of pregnancy in women less than 18 years old. Obstet Gynecol 2000; 96: 962-6.

36. Phipps MG, Sowers M. Defining early adolescent childbearing. Am J Public Health 2002; 92: 125-8.

37. Zabin S, Kiragu K. The health consequences of adolescent sexual and fertility behaviour in sub-Saharian Africa. Stud Fam Plann 1998; 29:210-32.

38. Fraser AM, Brockert JE, Ward RH. Association of young maternal age with adverse reproductive outcomes. $N$ Engl $\mathrm{J}$ Med 1995; 332: 1113-7.

39. Karabulut A, Ozkan S, Bozkurt AI, Karahan T, Kayan S. Perinatal outcomes and risk 
factors in adolescent and advanced age pregnancies: comparison with normal reproductive age women. J Obstet Gynaecol 2013; 33(4):346-50.

40. Liran D, Vardi IS, Sergienko R, Sheiner E. Adverse perinatal outcome in teenage pregnancies: is it all due to lack of prenatal care and ethnicity? J Matern Fetal Neonatal Med 2013; 26(5): 469-72.

41. Gortzak-Uzan L, Hallak M, Press F, Katz M, Shoham-Vardi I. Teenage pregnancy: risk factors for adverse perinatal outcome. $J$ Matern Fetal Med 2001; 10(6): 393-7.

42. Ganchimeg T, Mori R, Ota E, et al. Maternal and perinatal outcomes among nulliparous adolescents in low- and middle-income countries: a multi-country study. BJOG 2013; doi: 10.1111/1471-0528.12391.

43. Conde-Agudelo A, Belizán JM, Lammers C. Maternal-perinatal morbidity and mortality associated with adolescent pregnancy in Latin America: Cross-sectional study. Am J Obstet Gynecol 2005; 192(2):342-9.

44. Kabakyenga JK, Östergren PO, Turyakira E, Mukasa PK, Pettersson KO. Individual and health facility factors and the risk for obstructed labour and its adverse outcomes in south-western Uganda. BMC Pregnancy Childbirth 2011; 11:73. doi: 10.1186/14712393-11-73.

45. Scholl TO, Hediger ML, Belsky DH. Prenatal care and maternal health during adolescent pregnancy: a review and meta-analysis. $J$ Adolesc Health 1994; 15: 444-56.

46. Ikamari L, Izugbara C, Ochako R. Prevalence and determinants of unintended pregnancy among women in Nairobi, Kenya. BMC Pregnancy Childbirth 2013; 13:69. doi: 10.1186/1471-2393-13-69.

47. Singh A, Mahapatra B. The consequences of unintended pregnancy for maternal and child health in rural India: evidence from prospective data. Matern Child Health J 2013; 17(3):493-500.

48. Singh A, Chalasani S, Koenig MA, Mahapatra B. The consequences of unintended births for maternal and child health in India. Popul Stud (Camb) 2012; 66(3):223-39.

49. Wado YD, Afework MF, Hindin MJ. Unintended pregnancies and the use of maternal health services in southwestern
Ethiopia. BMC Int Health Hum Rights 2013; 13(1):36.

50. Feresu SA, Harlow SD, Welch $K$ and Gillespie BW. Incidence of stillbirth and perinatal mortality and their associated factors among women delivering at Harare Maternity Hospital, Zimbabwe: a cross-sectional retrospective analysis. BMC Pregnancy and Childbirth 2005; 5:9. http://www.biomedcentral.com.

51. Emmanuel T, Notion G, Gerald S, Addmore C, Mufuta T, Simukai Z. Determinants of perinatal mortality in Marondera district, Mashonaland East Province of Zimbabwe, 2009: a case control study. Pan Afric Med J 2011; 8:7. http://www.panafrican-medjournal.com/

52. Getachew B, Yifru B. Perinatal mortality and associated risk factors: a case control study. Ethiopian J Health Scie 2012; 22(3): 153-162.

53. Feresu SA, Welch K, Gillespie B, Harlow SD. Incidence of and sociodemographic Risk Factors for Stillbirth, Pre-term birth and Low Birth Weight in Zimbabwean Women. Paediatr Perinat Epidemiol 2004; 18:154-163.

54. Andersson T, Berhane Y, Wall S, Hogberg U. The impact of neonatal mortality on subsequent survival in rural Ethiopia. Ann trop pediatr 2002; 22: 25-32.

55. Lumbiganon $\mathrm{P}$, Panamonta $\mathrm{M}$, Laopaiboon $\mathrm{M}$, Pothinam S, Patithat N. Why are Thai official perinatal and infant mortality rates so low? Int J Epidemiol 1990; 19:997-1000.).

56. WHO Perinatal and Neonatal Mortality for the Year 2000: Country, Regional and Global Estimates. WHO; Geneva: 2006.

57. Mbaruku G, van Roosmalen J, Kimondo I, Bilango F, Bergström S. Perinatal audit using the 3-delays model in western Tanzania. Int $J$ Gynaecol Obstet 2009; 106(1):85-8.

58. Kramer M S. The epidemiology of adverse pregnancy outcomes; an overview. J Nutr 2003; 133 (Suppl 2):1592-96.

59. Devlieger H, Martens G, Bekaert A. Social inequalities in perinatal and infant mortality in the northern region of Belgium (the Flanders). Eur J Public Health 2005; 15(1):15-9

60. Zilberman B. Influence of short interpregnancy interval on pregnancy outcomes. Harefuah 2007; 146(1):42-7, 78. 
61. Shachar BZ, Lyell DJ. Interpregnancy interval and obstetrical complications. Obstet Gynecol Surv 2012; 67(9):584-96.

62. Stein W, Hawighorst T, Wenzlaff P, Emons G. The impact of the time interval between two successive deliveries in an obstetric unit in terms of the mode of each delivery and the rate of perinatal mortality. $J$ Perinat Med 2011; 40(1):63-8.

63. Titaley CR, Dibley MJ, Agho K, Roberts CL, Hall J. Determinants of neonatal mortality in Indonesia. BMC Public Health 2008; 8:232. doi: 10.1186/1471-24588-232.

64. Smith GC, Pell JP, Dobbie R. preterm birth and neonatal death: retrospective cohort study. BMJ 2003; 327(7410):313.

65. Sachar RK, Soni RK. Perinatal mortality in rural Punjab--a population-based study. J Trop Pediatr 2000; 46(1):43-5.

66. Hussaini KS, Ritenour D, Coonrod DV. Interpregnancy intervals and the risk for infant mortality: a case control study of Arizona infants 2003-2007. Matern Child Health J 2013; 17(4):646-53.

67. Nabukera SK, Wingate MS, Kirby RS, et al. Interpregnancy interval and subsequent perinatal outcomes among women delaying initiation of childbearing. J Obstet Gynaecol Res 2008; 34(6):941-7.

68. Wang PD, Lin RS. Perinatal mortality in Taiwan. Public Health 1999; 113(1):27-33. 